\title{
Escola mista nos primeiros anos da República: das Escolas Isoladas aos Grupos Escolares (Pará/Brasil, 1890-1901)
}

Coeducational school in the early years of Republic: from Isolated Schools to School Groups (Pará/Brasil, 1890-1901)

Escuela mixta en los primeros años de la República: de las Escuelas Aisladas a los Grupos Escolares (Pará/Brasil, 1890-1901)

Clarice Nascimento de Melo

Universidade Federal do Pará (Brasil)

https://orcid.org/0000-0001-7287-5648

http://lattes.cnpq.br/7497279574536104

mnclarice@gmail.com

\section{Resumo}

A escola mista dos primeiros anos da república paraense é o objeto deste texto. Intenciona-se com ele apresentar o percurso histórico que seguiram essa escola que reuniu meninos e meninas no mesmo espaço escolar, com destaque aos passos inicialmente titubeantes nas escolas primárias isoladas até se consolidarem nos grupos escolares, que marcaram a proposta modernizadora do projeto de educação nacional. Utiliza-se do método indiciário, que busca sinais dos movimentos colidentes na montagem da escola mista, presentes privilegiadamente nos documentos de governo - como Decretos, Portarias - e na revista A Escola. Um dos argumentos presentes no estudo está na relação existente entre a participação efetiva das mulheres na educação e a possibilidade de criação dessas escolas.

Palavras-chave: Escola mista. Mulheres. Educação republicana. 


\begin{abstract}
The coeducational school in the early years of Pará republic is the object of this article. It intends to present the historical course followed by this school which congregated boys and girls in the same school space, highlighting the initially faltering steps in isolated primary schools until their consolidation as school groups that marked the modernizing proposal of the national education project. This research used the indiciary method, which seeks for signs of colliding movements in assemblage of coeducational school that are present in government documents such as Decrees, Ordinances - and in the magazine A Escola. One of the arguments in the study is the relationship between the effective participation of women in education and the possibility of creating such schools.
\end{abstract}

Keywords: Coeducational School. Women. Republican education.

\title{
Resumen
}

La escuela mixta de los primeros años de la república paraense (Pará, Estado de Brasil) es el objeto de este texto. La intención es presentar el recorrido histórico que siguieron esa escuela que reunió niños y niñas en el mismo espacio escolar, con realce a los pasos inicialmente titubeantes en las escuelas primarias aisladas hasta que se consoliden en los grupos escolares, que marcaron la propuesta de modernización del proyecto de educación nacional. Se vale del método indiciario, que busca señales de los movimientos impactantes en el montaje de la escuela mixta, privilegiadamente presente en documentos gubernamentales - como Decretos, Ordenanzas - y en la revista 'A Escola'. Uno de los argumentos presentes en el estudio está en la relación existente entre la participación efectiva de las mujeres en la educación y la posibilidad de creación de esas escuelas.

Palabras-clave: Escuela mixta. Mujeres. Educación republicana. 


\section{Introdução}

O Estado do Pará apresentou ao país instituído republicano, a primeira regulamentação do ensino, por meio do Decreto n. 149 de 7 maio de 1890 (Pará, 1890). Com ela a escola mista primária paraense passou por alterações em sua organização. Ao longo da primeira década republicana a escola mista também foi reconfigurada, mantendo inicialmente reservas e contradições para, em seguida, se tornar mais expressiva na sociedade, o que apontou para um descontínuo do processo histórico. Não só a organização escolar, mas também os sujeitos foram redimensionados no cenário educativo.

A primeira década da escola mista republicana esteve permeada por ambiguidades presentes nos discursos e ações que, em um momento foi a negada, em outro foi assumida como possibilidade na educação. Isto pode ser visto pela recusa do poder público em relação a esse tipo de escola, no movimento inverso, pela demanda da população por escolarização e, ainda, pelo redimensionamento das relações cotidianas entre homens e mulheres. Após assumir o poder, o governo republicano tomou para si o discurso do moderno, associado à ideia de progresso e à mudança. De modo contraditório, no que se relaciona ao polêmico tema da coeducação dos sexos e da escola mista, o mesmo manteve-se reticente no primeiro momento para, em seguida, voltar a inseri-la como prática escolar.

Em uma tentativa de percorrer essas contradições, intenciona-se, neste estudo, apresentar os meandros da inserção da escola mista no projeto republicano paraense, problematizando suas imprecisões em relação à junção de meninas e meninos no mesmo tempo e espaço escolar, apontando momentos de recusa, em seus primeiros anos, nas escolas isoladas para, em seguida, se expandir e alcançar os grupos escolares. Destaca-se, nesse percurso, o protagonismo das mulheres - professoras e alunas - na permanência da escola mista paraense. Para isso busca-se sinais dos movimentos colidentes na montagem da escola mista, presentes privilegiadamente nos documentos de governo - como Decretos, Portarias - e na revista A Escola.

Percebe-se que, do ponto de vista econômico e social, a instituição do regime republicano no Pará não trouxe rupturas à sociedade paraense, pois as estruturas econômicas e sociais permaneceram quase intactas No entanto, o projeto educacional foi reordenado, e com ele as práticas da escola mista, juntando meninos e meninas no mesmo ambiente escolar, se alteraram, e, com a participação efetiva das mulheres na docência, passaram das escolas isoladas aos grupos escolares.

\section{A escola republicana dos primeiros anos}

Como um sinal expressivo do compromisso de modernização da educação, a escola paraense foi redesenhada sob os marcos do republicanismo. Organizado o Estado Confederado do Pará, a meta de aproximá-lo dos grandes centros urbanos do país exigia muitas tarefas, dentre elas, e destacadamente, estava a de erigir o ideário da ordem e do progresso por meio da educação. Intelectuais republicanos se propuseram a trazer alterações significativas para o projeto educacional no Pará e foi com a adesão efetiva a esse regime que a aliança se realizou ao menos nas prescrições. Um dos impulsos desse projeto seria a necessidade da "[...] formação de uma elite de doutores coesa, que se colocasse à frente dos negócios públicos e da construção do poder de um Estado Republicano nascente" (SARGES, 2010, p. 82).

Do mesmo modo que a urbanização foi um marco de distanciamento do passado imperial, a educação também se prestou a esse serviço. O discurso crítico empreendido por republicanos, em relação às ações do governo imperial no campo educativo, caracterizou publicamente a escola imperial como iníqua e desorganizada, portanto, substituível por um novo projeto. As falas nessa direção atravessaram as primeiras décadas republicanas. A professora Marianna Vianna, em seu relatório de ensino, publicado na revista "A Escola", declara a sua percepção sobre as qualidades empreendidas na educação pelo projeto republicano: 
É preciso considerar que há sete annos atraz, quando proclamou-se a Republica, a instrucção primaria achava-se no mais deplorável estado, [...] É preciso considerar a mudez absoluta em que vivia a escola paraense, e poderemos então aquilatar o grau de desenvolvimento d'este importante ramo dos negócios públicos (Revista a Escola, 1901a, p. 20).

Esse ideário foi articulado nos discursos e nas práticas que emergiram desde os primeiros anos republicanos. Veríssimo (1891), eminente intelectual paraense, contribuiu sobremaneira para a implementação da educação como política pública privilegiada no governo. Sua fala apontou para a tentativa de consolidar a ideia da educação como eixo central do projeto de modernização da sociedade, como é possível ver nesse trecho:

Quaisquer que sejam as divergências de escola, sobre os métodos, os sistemas, a organização, o grau de eficácia, o modo de distribuição do ensino público, o certo, o incontestável, o definitivo é que a prosperidade nacional não pode repousar sobre outra base que não a instrução pública (Veríssimo, 1891, p. 8).

Os primeiros anos da educação republicana remetem às alterações nas diretrizes estaduais, principalmente em relação à reorganização do ensino público em seus vários níveis. Em 1890, no governo de Justo Leite Chermont, e antes mesmo de ser promulgada a Constituição paraense, a instrução pública obteve regulamentação específica. Estando José Veríssimo à frente da Direção Geral da Instrução Pública, pôde transformar em discurso oficial suas ideias para a formação educativa das classes populares. Com a justificativa de que a educação esteve até o final do império regida "por legislação confusa, contraditória e mutilada pelas reformas parciais e incompletas realizadas sem plano e sem ordem", foi efetivado o Regulamento da Instrucção Pública e Ensino Especial do Estado do Pará, pelo Decreto 149, de 7 de maio de 1890 (Pará, 1890). Com esse fundamento, foi decretado que:

O ensino publico do Estado Confederado do Pará comprehende: Ensino primário. Ensino secundário. Ensino profissional ou technico.

O ensino primário é dado: Nas escolas elementares. Nas escólas primarias. No collegio do Amparo. No Instituto paraense de educandos e artífices. Nas escólas nocturnas para adultos ou outros estabelecimentos que por sua natureza e cathegoria distribuam o ensino assim denominado n'este regulamento.

O ensino secundário é dado: No Lyceu Paraense em um curso de preparatórios exigidos para a matricula nos cursos superiores da República. Nas escolas normaes para a formação de professores de ambos os sexos [...] (Pará, 1890, não paginado).

Especificamente em relação ao ensino primário, a divisão foi prevista em escolas elementares e escolas populares. As escolas elementares seriam instaladas em localidades pequenas, com número de alunos e alunas inferior a 80 , duração prevista de ao menos três anos de curso e funcionamento em 4 horas de aula no turno da manhã. As escolas populares possuíam o curso primário integral (elementar, médio e superior), em seis anos; classificam-se em escolas de primeira [freguesias e vilas], segunda [cidades] e terceira entrância [capital], com frequência de ao menos 80 crianças em idade escolar e, com isso se criaria uma escola para cada sexo, com funcionamento em 3 horas e meia no turno da manhã, 2 horas à tarde (Pará, 1890). 
Sem princípios definidos em relação à educação laica, à obrigatoriedade ou à gratuidade do ensino, o documento indicou a apreciação da centralização do poder estatal. A autonomia do Estado em relação à Igreja foi dimensionada no ano seguinte à reforma, nos termos da Constituição do Estado do Pará, de 22 de junho de 1891, que instituiu a laicidade do ensino ministrado nos estabelecimentos públicos (Pará, 1891).

Em relação ao movimento reformista da educação republicana brasileira, o Estado do Pará tomou a dianteira na promulgação de seu documento orientador do ensino, o que lhe confere um pioneirismo nas ações diretivas para a educação no Brasil. O Regulamento de maio de 1890 foi o divisor de águas entre o projeto imperial e o republicano para a educação no Pará.

A despeito da antecipação dessa reforma em relação às empreendidas no Rio de Janeiro e em São Paulo, as marcas na educação nacional foram impressas pelos documentos elaborados nesses grandes centros urbanos, controladores do poder político e econômico e, portanto, aptos à difusão de ideias. A Reforma de Benjamim Constant, do Distrito Federal (Rio de Janeiro), instituída pelo Decreto 981, de 8 de novembro de 1890 e a Reforma de Caetano de Campos de São Paulo, pelo Decreto de 8 de setembro de 1892, foram notadas como modelares para a educação republicana. A primeira é destacada pelo estabelecimento da gratuidade, pela laicidade do ensino, pela distribuição do ensino primário em dois graus e pela manutenção das escolas separadas para meninos e meninas; a segunda se notabilizou pela adoção das escolas-modelo e dos grupos escolares, que também mantinham a separação dos sexos (Carvalho, 2003; Veiga, 2007). Ambas se aliaram aos ideais republicanos que sedimentaram as bases da escola republicana brasileira.

Essa variedade de experiências foi possível em decorrência da descentralização federativa que possibilitou que emergissem projetos pedagógicos originais em cada estado. Essa ideia foi consolidada pela Constituição Brasileira de 1891. Nela estava determinado que somente o ensino superior fosse de responsabilidade do governo federal, ficando os demais níveis de ensino sob a administração das Secretarias do Interior de cada estado, mantendo a autonomia das unidades federativas. A preocupação mais efetiva com a construção de um projeto nacional iniciou-se em 1930, com a criação do Ministério da Educação e Saúde, durante o governo de Getúlio Vargas (Veiga, 2007). Até então, o valor de uma educação nacional estava sendo engendrada por intelectuais brasileiros. Destaca-se o empreendimento do paraense José Veríssimo que, em 1890, publicou no Pará a primeira edição de seu livro "A Educação Nacional", , apresentando argumentos estratégicos para, com a educação de traços típicos da nossa cultura, construir-se um sentimento nacional (Veríssimo, 1906).

Impulsionadas pela intenção de construir uma identidade nacional, as reformas da instrução pública republicana se pautaram, cada uma a seu modo, pelo modelo educacional que imprimia o estabelecimento dos limites da instrução primária, ou sua divisão e regulamentação, a introdução da instrução profissional no ensino primário, a educação nacional e cívica infantil, o auxílio a alunos pobres, a obrigatoriedade e a liberdade do ensino primário, higiene escolar e construção de edificações escolares (Thomaz Neto \& Braga, 2002).

Ao final da primeira década republicana, e desta vez sob a influência do modelo educacional paulista, o ensino primário paraense foi novamente reorganizado, desta feita, pelo Decreto 625, de 2 de janeiro de 1899, que instituiu o Regulamento Geral do Ensino Primário, o qual estabelecia que o ensino público deveria ser gratuito, leigo e uniforme, e passaria a ser ministrado em escolas isoladas, nos locais:

onde se verifica a existência de mais de 20 creanças no caso de receberem a instrucção; em escolas-modelo anexas à Escola Normal, destinadas não só ao ensino primário como ainda dos exercícios práticos do ensino dos alumnos mestres [...] (Pará, 1899a, não paginado).

\footnotetext{
${ }^{1}$ A segunda edição de seu livro foi publicada no Rio de Janeiro, em 1906.
} 
As escolas públicas isoladas ficaram divididas em elementares (onde houvesse mais de vinte crianças aptas a receberem instrução) e complementares (onde houvesse ao menos cinquenta crianças para cada classe), divididas em dois cursos: o médio e o superior, cada um com duração de dois anos (PARÁ, 1899a). Com ele o ensino primário ocorreria também nos grupos escolares.

Para além da formalidade das leis, intelectuais, bacharéis de escolarização superior, lentes catedráticos das escolas secundárias, professoras e professores normalistas, estudantes de escolas secundárias, registraram suas opiniões e suas ideias em revistas, jornais, em relatórios e outros. Diversas falas marcaram uma época, formaram gerações e revelaram conjunções, tensões e conflitos de opiniões e de práticas que ajudaram a constituir universos educativos. Em um cenário que teve como pano de fundo a adesão do Pará à proclamação da República, homens e mulheres vivenciaram, projetaram, discutiram, e novamente vivenciaram a escolarização. Foi nesse ambiente que a República paraense refez a escola mista.

\section{Um passo titubeante das escolas mistas nas escolas primárias isoladas}

As imprecisões da escola mista republicana, entre 1890-1901, quando esta se espraia para todo o estado, inclusive nos grupos escolares, são manifestações das contradições existentes entre o discurso fundamentado na modernização e as práticas conservadoras em relação a esse tipo de escola, que se defronta com a presença incisiva de professoras na regência do ensino e com a equidade entre os sexos na discência.

O Decreto n. 149, de 7 de maio de 1890 inibia a prática das escolas mistas, apontando, em alguns discursos, para uma espécie de retorno aos padrões anteriores à sua institucionalização feita em 1880. Nesse documento a escola mista não foi prescrita, tendo sido reguladas apenas as escolas femininas e masculinas. Não ignorando a existência e a possibilidade da promiscuidade dos sexos, o recurso para sua inclusão com regularidade em todo o estado foi previsto por meio da sua permissão, indicada apenas no caso da inclusão de meninos em escolas do sexo feminino. Essa indicação manteve a junção dos sexos na escola primária exclusivamente às professoras, do mesmo modo que nas indicações para as escolas mistas. Foi permitida a introdução das salas mistas em todas as escolas elementares; nas escolas populares ficou restrito aos quatro primeiros anos dos cursos elementar e médio, excluindo os dois últimos anos do curso superior. Em ambas, o limite de idade imposto aos meninos permaneceu nos dez anos, em diálogo com o Parecer de Rui Babosa, de 1882, no qual a coeducação dos sexos foi prevista com esse limite (Pará, 1890).

José Veríssimo (1981), em seu relatório de gestão, frente à Direção da Instrução Pública do Pará, apresentou mais uma vez o ofuscado tratamento que recebia a escola mista. Nele foram mostradas as estatísticas das escolas primárias: em 1891, o número de escolas públicas primárias totalizava 417 , sendo 276 para o sexo masculino, e 141 para o sexo feminino (Veríssimo, 1891). Como se vê, as escolas mistas foram excluídas dos números e do público.

Apesar de não constarem nas estatísticas e na legislação, as escolas mistas permaneceram na vida escolar paraense. Tem-se a indicação de que, a partir do ano de 1892 e durante toda a década, o governo republicano paraense expandiu o ensino público com escolas mistas. Isso pode ter ocorrido ou por conta da mudança no governo estadual, ou por força das práticas sociais.

É visível a expressão numérica que a escola mista foi ganhando - principalmente a partir de meados dessa década - no processo de expansão do ensino público primário no Pará republicano, em relação às duas décadas anteriores ${ }^{2}$. Mas, é necessário considerar algumas singularidades nesse processo.

\footnotetext{
${ }^{2}$ Se no final do período imperial, o número de escolas públicas mistas se reduzia a 5 , durante o governo republicano, de 1892 a 1901, foram criadas mais de 160 escolas mistas em todo o estado.
} 
Nota-se que um número considerável dessas escolas foi extinto em algumas localidades, o que aponta para uma fragilidade institucional das mesmas, que pode ser resultante ou da flutuação das demandas, ou da recusa desse modelo e predileção das escolas unissexuais.

Também é perceptível que a sua criação em várias localidades teve como origem as escolas já existentes, masculinas ou femininas, o que, nesses casos, não contribuiu para a ampliação numérica do quadro de escolas públicas, mas gerou um diferencial na composição escolar, nas localidades onde isso ocorreu. A conversão de escolas unissexuais para mistas parece um sintoma da desestruturação de um padrão escolar.

As conversões de escolas também apresentam uma situação instigante. Elas sugerem, por um lado, a permanência dos professores no magistério misto e, por outro, a ampliação da participação das meninas em escolas masculinas. Em Marapanim a escola mista foi convertida de masculina, e permaneceu regida por professor; a de Mututy, em Breves, e a de Baturité, em Macapá, também foram convertidas de escolas masculinas e, em caso provável de os professores não terem sido substituídos por professoras, somam-se três o número de escolas mistas regidas por professores. Esses casos corrompem o prescrito na legislação do período, que previu somente a docência feminina para essas escolas - apesar de não proibir a masculina - o que, mais uma vez deixa marca da força das práticas educativas subvertendo a ordem estabelecida.

Por fim, sua expansão numérica bem maior no interior do estado que na capital significa mais um indicador da relutância do governo republicano em tornar as escolas mistas centrais na organização do ensino. Sendo privilegiadas para marcar a presença do poder público por todo o estado, elas aparecem como um artifício, ao mesmo tempo em que foram subsumidas em territórios com menor expressividade que a capital.

Ao final dessa década a escola mista voltou a ser lugar de controle e ordenação. Isso ocorreu por meio do Decreto n. 625, de 2 de janeiro de $1899^{3}$, o qual estabelecia a possibilidade de criação de escolas mistas e as integrou à organização do ensino primário (Pará, 1899a)

Esse documento é significativo por indicar dissensos na institucionalização dessa escola, assim como a contradição entre o pretensamente novo e o tradicional, no campo educativo.

Com significado de mudança na estrutura educativa, as escolas mistas seriam caracterizadas como aquelas "art. 59 [...] em que poderão ser admittidas as creanças de um e outro sexo" (Pará, 1899a), o que resvala em direção da coeducação dos sexos. Contudo, a relação de meninos e meninas na escola ainda era sutilmente apresentada como um vetor de moralidade, que deveria ser evitada.

Ainda nesse documento permaneceu a restrição em relação à junção dos sexos na escola primária pública, em três modos:

a) Na proibição de professores lecionarem para meninas em escolas mistas ou femininas, pois essa prerrogativa permanecia exclusiva às professoras;

b) Na provisoriedade imputada a elas, condicionada ao fato da frequiência não ser suficiente para a criação de duas escolas unissexuais;

c) No limite fixado apenas nas escolas isoladas - elementares e complementares - excetuando os grupos escolares. Do mesmo modo, a proibição da matrícula de meninas em escolas de meninos e de matrícula de meninos em escolas de meninas, nas escolas formalmente unissexuais, representam um valor contido nas estruturas formais que balizam a separação dos sexos e procuram garantir a permanência da tradição (Pará, 1899a).

\footnotetext{
${ }^{3}$ Como o conjunto de leis encontrado nos arquivos está incompleto em alguns anos, é possível que haja algum documento que tenha feito menção à organização das escolas mistas, anteriormente a esse; não tendo sido encontrado na pesquisa, tratamos do retorno dessa escola nas prescrições legais, a partir do documento referenciado.
} 
A forma de organização de meninos e meninas na escola mista também pode ser explicada como reação contrária a ela. Com a possibilidade da conjunção dos sexos nos mesmos espaços, as restrições foram impostas na divisão de horários, separando as meninas no turno da manhã e os meninos no turno da $\operatorname{tarde}^{4}$, assinalando uma reação negativa em relação à efetuação da promiscuidade dos sexos, como é possível observar:

Nas escolas mixtas a instrucção será dada promiscuamente aos meninos e ás meninas, em duas sessões diárias de três horas; - a primeira das 7 $1 / 2$ ás $101 / 2$ da manhã, destinada ás alumnas, a segunda das 2 ás 5 da tarde, destinada aos alumnos [...] (Pará,1899a).

Duas peculiaridades podem ser destacadas nesse formato. Em primeiro lugar, para cumprir a separação, os alunos e as alunas das escolas mistas tiveram o tempo de estudos regulares reduzido em 1 hora em relação às escolas unissexuais, que praticavam 4 horas de estudos pela manhã. Em segundo lugar, a divisão da escola em dois turnos, além de imputar a dupla jornada de trabalho às professoras de escola mista, ainda lhes acrescentou hora a mais de trabalho, sem a devida remuneração.

Essa disparidade não passou despercebida. João Lemos publicou na revista "A Escola" sua reclamação diante excesso de trabalho da professora "[...] que pretensamente trabalha seis horas por dia [...] não entrando na linha de conta a recompensa pecuniária, que não soffreu augmento algum" (Revista a Escola, 1901b, p. 207). É possível que reclamações desse tipo tenham conduzido a uma mudança na remuneração por meio legal, ocorrida em junho desse ano. Depois dela foram refeitos os salários das professoras, o qual se tornou superior em relação aos professores de escolas unissexuais nas escolas de $3^{\mathrm{a}}$ entrância, da capital do estado, e $2^{\mathrm{a}}$ entrância, das cidades do interior. Nas escolas elementares de $1^{\mathrm{a}}$ entrância, das vilas e freguesias, a desigualdade permaneceu.

Acompanhando o movimento ascendente da criação de escolas mistas, o final do século XIX também foi efervescente na discussão sobre a reunião de meninas e meninos na escola. No Brasil, associada ao conceito da coeducação dos sexos - a escola mista se expandiu como pauta de discussão em âmbito nacional. A revista "A Escola", divulgando esse debate, trouxe para o domínio local a dimensão que o tema vinha tomando. No ano de 1900, o Congresso Nacional de Educação definiu suas teses, dentre elas:

$27^{\circ}$. Coeducação dos sexos nas escolas e nos institutos de ensino primário.

$29^{\circ}$. Organização de institutos de ensino secundário para o sexo masculino.

$39^{\circ}$. Coeducação dos sexos nos institutos do ensino secundário.

$51^{\circ}$. Coeducação dos sexos nos institutos de ensino superior (Revista a Escola, 1900a, não paginado).

A discussão do tema da coeducação dos sexos foi acompanhada pelo Pará, que o propôs como tese para a primeira reunião do Congresso Pedagógico, aqui restrito ao ensino primário e ao ensino normal (Revista a Escola, 1900c).

A consolidação desse tipo de escola no estado pode ser notada na estatística escolar do ano de 1900, que contou entre as 577 escolas públicas primárias, com 133 mistas, sendo 120 elementares e 13 complementares (Veríssimo, 1906; Revista a Escola, 1900b).

Nessas escolas participaram na docência professoras nomeadas pelo governo do estado. Se o movimento ascendente na formação de professoras criou condições para a institucionalização de escolas mistas - por essas só poderem ser regidas por professoras - em

\footnotetext{
${ }^{4}$ Não foi possível verificar a discussão sobre a dupla jornada de trabalho das professoras nas escolas mistas, e se essa divisão se realizou efetivamente.
} 
um sentido inverso, a criação ascendente de escolas mistas também possibilitou a ampliação da participação das mulheres nas escolas primárias públicas.

A participação de professoras na escola mista, numericamente ascendente, é pensada como prática de resistência. Apropriando-se do discurso da docência associada à maternidade, como forma de garantir sua sobrevivência e obter outros poderes no campo de trabalho (FRAISSE; PERROT, 1994a), as professoras ocuparam o espaço da docência de meninos e meninas. A representação da professora/mãe, imputadas a elas pelo discurso masculino se revelou como um elemento mediador entre as interdições e as negociações do trabalho docente feminino, além dos tempos e luares da mulher na educação.

\section{Inserção da Escola Mista nos Grupos Escolares}

Os grupos escolares foram criados em conexão com o projeto nacional republicano. Implantado em São Paulo em 1893 e estendido para outros estados no final do século XIX e início do $\mathrm{XX}^{5}$, esse modelo de escola pública tornou-se um dos ícones da ruptura com o passado imperial, qualificado como lugar da higiene, do controle e da racionalidade pedagógica. Incorporaram o princípio das classes seriadas reunidas sob uma só direção, com métodos pedagógicos modernos, articularam saberes e fizeram circular o projeto educativo republicano. Sua implantação se configurou como prática e representação da nação brasileira, formada por uma sociedade ordeira e progressista. Construídos como alegorias monumentais, sua organização espacial traduziu sua função pedagógica de ensinar, conduzindo comportamentos e a interiorização das representações sociais (Faria Filho \& Vidal, 2000, p. 25). O controle do tempo - valor experienciado pelas sociedades industrializadas - também possuiu o sentido de naturalizar em todos os lugares, o urbano. Acopladas à concepção de ensino, as práticas escolares empregaram essa ideia na distribuição de horários e turnos. Lopes (2006, p. 5) define melhor esse sentido:

Opondo-se ao tempo cíclico e amplo das concepções agrárias, a nova realidade urbana e burguesa pressupõe uma nova formação: o tempo linear, do trabalho, da disciplina, do início e do fim, da hierarquia e da ordem. Espaço e tempo serão reordenados, nesse sentido, espaço e tempo escolar serão estruturados para essa formação.

Planejados em ordem simétrica, com espaços para lazer, higiene, estudos e controle do trabalho docente, os grupos escolares se tornaram o núcleo organizativo de uma nova cultura escolar, que foi sedimentada nas primeiras décadas do Brasil republicano por meio da organização de novos tempos, rotinas e diretrizes que, como ensina Júlia (2001, p. 15) permitiram "a transmissão desses saberes e a incorporação desses comportamentos, normas e práticas, de acordo com as finalidades desejadas". Com essa nova cultura incorporada nos grupos escolares "[...] todo o espaço escolar convertia-se em ambiente educativo, moralizante e civilizador" (Souza, 1998a, p. 49).

No Estado do Pará os grupos escolares foram institucionalizados com o Regulamento Geral do Ensino Primário de 1899. A instalação, segundo ele, poderia ser feita "nos distritos escolares da capital e nas sedes dos municípios, com o critério de haver pelo menos quatro escolas de ambos os sexos, no raio fixado para a obrigatoriedade" (Pará, 1899a); essas características permitiam ao Governo reuni-las, fazendo-as funcionar em um só prédio. Com

\footnotetext{
${ }^{5}$ No Rio de Janeiro, o primeiro grupo escolar instalado data de 1897; no Pará, em 1899; no Maranhão, o sistema de grupos escolares foi instituído em 1903; em Minas Gerais, o primeiro grupo escolar da capital foi criado em 1906; no Rio Grande do Norte e no Espírito Santo, em 1908; em Santa Catarina, em 1911; na Paraíba, o primeiro grupo escolar foi inaugurado em 1916; no Piauí, as escolas reunidas permaneceram até 1922, ano da criação do primeiro grupo escolar. Com caminhos diferentes, o que agregava todos era a sua fundamentação na modernidade republicana (Pinheiro, 2002; Veiga, 2007).
} 
regime e método das escolas-modelo, os grupos escolares deveriam comportar no máximo 300 alunos de cada sexo, em sessões femininas e masculinas, com uma só direção (Pará, 1899a).

Como consequência desse documento foi inaugurado o primeiro Grupo Escolar no estado, na cidade de Alenquer, em 1899. Esses grupos foram numericamente ampliados nos anos subsequentes, chegando em 12 unidades em 1901. Ao contrário do que ocorreu em São Paulo, onde os grupos escolares foram criados para atender aos núcleos urbanos, como afirma Souza (1998a), no Pará o governo estadual previu a criação na capital, mas, por motivo não justificado, privilegiou a sua instalação em municípios interioranos. Em Belém os grupos escolares começaram a ter vida dois anos depois, em 1901.

De acordo com o documento que os originou, a sua organização ocorreu da reunião de escolas isoladas, femininas e masculinas já existentes, do que se presume que a meta da expansão do ensino não era central na integração dos grupos escolares nas comunidades; o desejo de sustentar a imagem do grupo escolar como representação do governo republicano se fazia presente na prescrição.

O projeto de construção do prédio do "Grupo Escolar José Veríssimo" é significativo, pois serve como indicador de como no Pará o projeto de modernização da escola republicana foi pensado.

Seguindo a ordem planificada, o movimento diário dos alunos começava com o acesso à escola pelos dois jardins. Já na entrada a separação dos sexos era feita. O caminho percorria um pátio acessível a uma única portaria que servia de fiscalização para ambos os lados. Após a primeira fiscalização feita na portaria, o passeio dos alunos terminava nas duas salas de estudo frontais às duas salas de banho. Os professores seguiam o mesmo percurso até o final do corredor, para assentar-se em seus gabinetes de trabalho, também divididos por sexo. Para os alunos e alunas que seguissem até o segundo pavimento, a mesma distribuição de salas de aula e salas de banho os esperava. Com o mesmo tamanho do espaço das duas salas dos professores no pavimento térreo, o gabinete do diretor finalizava o percurso.

A simetria entre as 8 salas de aula e as 8 salas de banho, presente nesse grupo escolar, fortaleceu o conceito de higiene que era um dos sustentáculos do projeto de modernização. $\mathrm{O}$ número de espaços para a higienização contrasta com a ausência de espaços coletivos para estudos, como biblioteca ou museu, pelo qual se vê que as variações nas práticas da escola mista ocorreram de acordo com o projeto educacional de cada estado, mas sem perder de vista o modelo paulista ${ }^{6}$.

Percebe-se que os primeiros grupos escolares paraenses mantiveram o princípio da organização escolar fundamentada na separação de meninas e meninos, o que é perceptível também na criação do grupo escolar da cidade de Alenquer:

Art. 1. As escolas publicas isoladas, complementares e elementares, creadas na cidade de Alenquer, passam a funccionar conjunctamente no prédio [grupo escolar] para esse fim arrendado pelo governo [...]

Art. 3. As aulas funccionarão em duas secções disctintas - a feminina das 7 1 $1 / 2$ ás 11 1 1/2 horas da manhã e a masculina de 1 ás 5 horas da tarde (Pará, 1899b, não paginado).

Sem edifício apropriado para separar espacialmente as secções femininas das masculinas, o documento previu que a separação fosse mantida em tempos diferenciados. Mantendo duas secções de funcionamento, garantia a permanência de meninas e meninos no grupo, mas com o padrão divisor de sexos. Logo, todo o curso primário, elementar e complementar, das escolas existentes na cidade foi abrigado no grupo escolar, em turmas separadas por sexo. O documento não indica quantas escolas deveriam ser agregadas ao grupo, portanto, não é possível afirmar se a equidade dos sexos foi um princípio mantido nesse e nos

\footnotetext{
${ }^{6}$ A arquitetura paulista deu exemplo marcante para a construção dos grupos escolares, como se percebe na afirmação seguinte: “[...] Em dois pavimentos contrastava com as habitações e a arquitetura da época, com um programa arquitetônico para oito salas de aula (quatro para cada sexo) e um reduzido número de ambientes administrativos” (Moreira, 2005, p. 41).
} 
outros grupos fundados nesse formato. Mas, está claro que com a expansão dos grupos escolares com essa configuração, as escolas mistas só poderiam ter existência nas escolas isoladas.

Como propagador de uma nova cultura escolar, os grupos escolares abrigavam um velho preceito: as diferenças sexuais eram referenciais para a organização da escola. Essa foi uma marca que se expandiu pelo Brasil, aplicado dos modelos do exterior, pois até o final do século XIX, essa era a característica das numerosas escolas construídas na Europa, como afirma Mayeur (1994).

O projeto para os grupos escolares de São Paulo foi o detonador dessa lógica. Eles apresentaram as seguintes características:

[...] Edificados simetricamente em torno de um pátio central ofereciam espaços distintos para o ensino de meninos e de meninas. À divisão formal da planta, às vezes, era acrescido um muro, afastando rigidamente e evitando a comunicação entre os dois lados da escola. Esses prédios tinham entradas laterais diferentes para os sexos. Apesar de padronizados em planta, os edifícios assumiam características diversas, sendo-lhes alteradas as fachadas. [...] A rígida divisão dos sexos, a indicação precisa de espaços individuais na sala de aula e o controle dos movimentos do corpo na hora de recreio conformavam uma economia gestual e motora que distinguia o aluno escolarizado da criança sem escola (Vidal \& Faria Filho, 2005, p. 25).

A separação dos sexos implantada nos grupos escolares paulistas instalou e divulgou a equidade do direito à educação entre meninas e meninos, pois estavam previstas sempre números iguais de salas para eles. No entanto, impediu a coeducação, como indica Souza (1998b, p. 47): "[...] a escola paulista, pública e laica não ousou avançar em relação aos padrões morais predominantes na sociedade". O movimento de inversão desse sentido só ocorreu em 1902, quando os programas de educação integral e de caráter enciclopédico foram facultados para ambos os sexos.

Bem cedo as contradições desse modelo foram postas na experiência dos grupos escolares paraenses. A partir de 1901 as primeiras cadeiras mistas foram incorporadas na organização de alguns Grupos, concomitante a alguns grupos escolares que permaneceram no formato anterior. A inauguração das classes mistas nos grupos paraenses foi feita na criação do grupo escolar da cidade de Óbidos, no interior do Pará:

Ficam creadas no grupo escolar da cidade de Óbidos cinco cadeiras do ensino primário, sendo uma complementar mista e duas elementares em cada uma das secções do mesmo grupo.

Art $4^{\circ}$. As aulas das cadeiras acima funccionarão em duas secções distintas - a feminina das $71 / 2$ ás 11 1/2 horas da manhã e a masculina de 1 ás 5 da tarde (Pará, 1901a, s/p.).

Com a justificativa de "[...] que a pratica tem demonstrado que o ensino complementar nos grupos escolares das cidades do interior póde bem ser dado em uma aula mista, commum ás duas secções, com economia para o Thesouro" (Pará, 1901b, não paginado), além de uniformizar os grupos escolares no Estado, as cadeiras mistas foram expandidas pelo governo estadual a outras localidades.

Embora a razão de ordem econômica fosse contundente na lógica do governo estadual em incorporar uma cadeira mista nos grupos escolares, outras dimensões desse processo podem dar conta da contradição dessa proposta em relação ao que era feito em outros estados brasileiros. A conjunção de alguns fatores, acredita-se, induziu esse processo.

Por um lado, encontra-se o discurso do governo e de intelectuais favoráveis à modernização da educação, a partir do formato dos grupos escolares, que mobilizou a aceitação desse projeto. Com 
os olhos voltados a essa experiência já realizada no exterior, a professora Mariana Vianna publicou seu relatório de ensino na revista $A$ Escola, explanando sobre a sua positividade:

A França, a Alemanha, os Estados-Unidos, a Hollanda, a Bélgica, a Suissa e a Inglaterra, dividem os estudos primários em cursos leccionados por professores especiaes para cada um d'elles, e grupam em grandes edifícios onde a hygiene brilha largamente, avultado número de alumnos e alumnas. Grandes vantagens de ordem econômico-pedagogica emanam dessa utilíssima organização escolar, a mais perfeita, racional e proveitosa que existe (Revista a Escola, 1901b, p. 20).

Esse e outros discursos reclamavam pela ordem e higienização do ambiente escolar e, principalmente, pela sua expansão da organização escolar, como se quer, perfeita e racional. Logo, a avaliação incluía a opção pelos grupos escolares e, consequentemente, o fim das escolas públicas isoladas.

Por outro lado, o governo republicano expandiu quantitativamente as escolas mistas pelo estado; no ano de criação dos grupos escolares essas escolas já possuíam dimensão expressiva na educação estadual, o que remete a sua naturalização na sociedade. Disso presumese que a prática do ensino misto impulsionou a introdução de cadeiras mistas para o interior dos grupos, a despeito da fixidez do projeto inicial em relação à separação dos sexos.

Como resultado desses dois fatores, percebe-se uma questão de ordem operacional. Se o os grupos foram projetados para reunir todas as escolas das cidades, e as mistas já faziam parte da organização do ensino, o movimento crescente das escolas mistas já criadas deveria trilhar em direção a esses grupos, mesmo com o limite inicial às escolas complementares.

Infere-se, com esses elementos, que as razões de ordem econômica foram importantes para justificar a criação de escolas mistas complementares, como uma solução para a pequena demanda por esse curso. Contudo, volta-se a argumentar que a presença expansiva de escolas mistas regidas por professoras, foi um fator preponderante na expansão dessa modalidade de ensino nos grupos escolares. Considera-se, para esse argumento, que as escolas complementares mistas foram criadas, principalmente com a conversão de escolas femininas já criadas, regidas por professoras, como é possível observar no quadro abaixo:

Quadro 1 - Escolas mistas em grupos escolares.

\begin{tabular}{|l|l|l|}
\hline \multicolumn{1}{|c|}{ Documento } & \multicolumn{1}{|c|}{ Nome/localidade } & \multicolumn{1}{c|}{ Convertida de } \\
\hline Decreto n. 941, de 23 de janeiro de 1901 & Óbidos & \\
\hline Decreto n. 966, de 23 de fevereiro de 1901 & $\begin{array}{l}\text { D. Romualdo de } \\
\text { Seixas/Cametá } \\
\text { Gonçalo Ferreira/Curuçá } \\
\text { Corrêa de Freitas/Bragança } \\
\text { Fulgêncio Simões/Alemquer } \\
\text { Santarém } \\
\text { Julio Cezar/Soure }\end{array}$ & $\begin{array}{l}\text { Escola feminina } \\
\text { Escola feminina } \\
\text { Escola feminina } \\
\text { Escola feminina } \\
\text { Escola feminina } \\
\text { Escola masculina }\end{array}$ \\
\hline Decreto n. 1009, de 4 de maio de 1901 & Maracanã & \\
\hline Decreto n. 1057, de 31 de julho de 1901 & Vigia & \\
\hline $\begin{array}{l}\text { Decreto n. 1067, de 12 de agosto de } \\
\text { 1901 }\end{array}$ & Belém & \\
\hline
\end{tabular}

Fonte: Pará. (1901a); Pará. (1901b); Pará (1901c); Pará (1901d); Pará (1901e). 
Então, se a escola de ambos os sexos regida por professores atendeu a uma demanda feminina por escolarização e foi um passo na ampliação da participação de meninas na escola; se a escola mista regida por professoras consolidou a feminização do magistério e, portanto, ampliou a participação das mesmas na escola, a escola complementar mista nos grupos escolares paraenses, por sua vez, atravessou a lógica do pertencimento da mulher na escola e representou um sinal da naturalização, em um primeiro momento, da equidade dos sexos e, posteriormente, do compartilhamento, entre homens e mulheres, dos espaços escolares.

O não espraiamento da escola mista para todos os grupos escolares do estado, assim como a incorporação da escola mista apenas na cadeira complementar do ensino primário, é um sinal de que permanecia a reticência em relação à junção de meninas e meninos na escola, a despeito de sua expansão pelo território estadual. Esse movimento de recusa e aprovação expressa mais um dissenso no percurso da institucionalização da escola mista aliado ao projeto de modernização da educação paraense, desta feita por meio dos grupos escolares, pois o projeto da coeducação dos sexos e o dos grupos escolares, apesar de fazerem parte do projeto nacional, chocaram-se na prática escolar, ora radicalmente, ora sutilmente.

As aulas mistas passaram a configurar os tempos e espaços dos grupos escolares paraenses. Os documentos apontam que dos 12 grupos escolares criados, 10 incorporaram as cadeiras complementares mistas; as exceções ficaram com dois grupos escolares localizados em Belém.

Esse foi um movimento adverso ao que ocorreu em outros estados brasileiros, que foram ainda reticentes em relação à incorporação da escola mista nos grupos escolares. Em São Paulo e no Rio de Janeiro, até ao menos o ano de 1902 permaneceu a prática da divisão sexual nos grupos escolares. Veiga (2007) apresenta a descrição desses grupos feita por um inspetor mineiro nesse ano, e nela percebe-se essa prática. Sobre o Grupo Escolar do Brás, de São Paulo, o inspetor notou que nele há pátios para recreios de ambas as secções. E elogiando a ordem, característica desses grupos, destacou:

É tal a ordem disciplinar observada nesses institutos que, dado o sinal de recreio pela sineta, a movimentação de saída é uniforme, ano por ano, sem o menor perigo de confusão ou de promiscuidade de sexos (Veiga, 2007, p. 245).

Logo, a expansão da escola mista nos grupos escolares paraenses, pode-se afirmar, ganhou uma singularidade no cenário nacional, por aglutinar, mesmo que de modo ambíguo, tanto em relação à organização do ensino, quanto aos padrões morais da época.

\section{Considerações finais}

Com a inserção nos grupos escolares e com a ampliação numérica por todo o Estado do Pará, a escola mista se consolidou como uma realidade no contexto paraense. A sociedade, com a pretensão de se tornar moderna, configurou a educação como um lugar de acerto dessa lógica, na qual a escola fundamentada em princípios coeducativos foi aliada a esse sentido. Os padrões sociais e educativos do Pará republicano foram construídos nessa perspectiva, também em um acerto da lógica contraditória entre as representações sociais do feminino que desassociavam as mulheres do campo intelectual e do mundo do trabalho e as necessidades materiais impulsionadas pelas novas ordens do capitalismo ascendente, que envolveram disputas por determinar conceitos, valores e modos de fazer a escola.

As escolas mistas republicanas, com singularidades e restrições, consolidaram a desestruturação de padrões pedagógicos, morais e profissionais rígidos, os quais redimensionaram e foram redimensionados pelos lugares e ações de mulheres. As rupturas que as mulheres fizeram no campo educativo romperam com estruturas mentais e sociais de seu tempo. As professoras que 
fizeram a escola mista alteraram o formato da escola, dentro de uma estrutura social historicamente sedimentada por relações de poder entre os sexos e de domínio masculino.

Aqui, professoras e alunas são percebidas como sujeitos privilegiados na efetivação da escola mista. Mas, claro, dividiram esse fazer, com outros sujeitos em diversos locais de poder. Percebe-se que na mudança histórica feita por meio dessa escola, ao reunir o mundo masculino e o mundo feminino, com suas diferenças, as mulheres tiveram um papel fundamental na experiência da coeducação dos sexos, pois com suas demandas de trabalho e estudo fizeram a escola mista como um lugar possível na educação paraense.

\section{Referências}

CARVALHO, M. M. C. (2003). Reformas da instrução pública. In: LOPES, E. M. T., FARIA FILHO, L. M., \& Veiga, C. G. 500 anos de educação no Brasil (pp. 225-252). Belo Horizonte: Autêntica.

FARIA FILHO, L. M., \& VIDAL, D. G. (2000). Os tempos e os espaços escolares no processo de institucionalização da escola primária no Brasil. Revista Brasileira de Educação, 14, 19-34. http://www.scielo.br/pdf/rbedu/n14/n14a03.pdf.

FRAISSE, G., \& PERROT, M. (1994). Introdução: ordens e liberdades. In: DUBY, G., \& PERROT, M. (Orgs.). História das mulheres. Tradução de Cláudia Gonçalves e Egito Gonçalves. Vol. 4: O século XIX. (pp. 9-15). Porto: Afrontamento.

JULIA, D. (2001, junho) A cultura escolar como objeto histórico. Revista Brasileira de História da Educação, 1(1), 9-43. Acessado em: http://www.rbhe.sbhe.org.br/index.php/rbhe/article/ view/273/281.

LOPES, J. J. M. (2006). Espaços e tempos escolares: algumas reflexões. [S.I: s.n.].

MAYEUR, F. (1994). A educação das raparigas: o modelo laico. In: DUBY, G., \& PERROT, M. (Orgs.). História das mulheres. Tradução de Cláudia Gonçalves e Egito Gonçalves. v. 4: O século XIX. (pp. 277-295) Porto: Afrontamento.

MOREIRA, A. Z. M. (2005). Um espaço pioneiro de modernidade educacional: Grupo Escolar "Augusto Severo" - Natal-RN - 1908-13. (Dissertação de Mestrado) Universidade Federal do Rio Grande do Norte, Natal.

PARÁ. (1981). Constituição do Estado do Pará, de 22 de junho de 1891. Atos e Decisões do Governo de 1891. Belém: Imprensa Oficial.

PARÁ. (1890). Decreto ${ }^{\circ}$ 149, de 7 de maio de 1890. Atos e Decisões do Governo de 1890. Belém: Imprensa Oficial.

PARÁ. (1899a). Decreto ${ }^{\circ}$ 625, de 2 de janeiro de 1899. Reorganiza o ensino primário do Estado. Atos e Decisões do Governo de 1889. Belém: Imprensa Oficial.

PARÁ. (1889b). Decreto n ${ }^{\circ} 722$, de 10 de junho de 1889. Cria na cidade de Alenquer, um grupo escolar. Atos e decisões do Governo de 1889. Belém: Imprensa Oficial. 
PARÁ. (1901a). Decreto ${ }^{\circ}$ 941, de 23 de janeiro de 1901. Atos e Decisões do Governo de 1901. Belém: Imprensa Oficial.

PARÁ. (1901b). Decreto n ${ }^{\circ}$ 966, de 23 de fevereiro de 1901. Atos e Decisões do Governo de 1901. Belém: Imprensa Oficial.

PARÁ (1901c). Decreto no 1009, de 4 de maio de 1901. Cria na cidade de Maracanã, um grupo escolar. Atos e decisões do Governo de 1901. Belém: Imprensa Oficial.

PARÁ (1901d). Decreto no 1057, de 31 de julho de 1901. Cria na cidade de Vigia, um grupo escolar. Atos e decisões do Governo de 1901. Belém: Imprensa Oficial.

PARÁ (1901e). Decreto n ${ }^{\circ}$ 1067, de 12 de agosto de 1901. Cria na cidade de Belém, um grupo escolar. Atos e decisões do Governo de 1901. Belém: Imprensa Oficial.

PINHEIRO, A. C. F. (2002). Da era das cadeiras isoladas à era dos grupos escolares na Paraíba. São Paulo: Universidade São Francisco; Autores Associados. (Educação contemporânea).

REVISTA A ESCOLA (1900a, maio), 1(1).

REVISTA A ESCOLA (1900b, junho), 1(2).

REVISTA A ESCOLA (1900c, agosto), 1(5).

REVISTA A ESCOLA (1901a), 4(19), 20.

REVISTA A ESCOLA (1901b), 4(20), 207.

SARGES, M. N. S. (2010). Belém: riquezas produzindo a Belle Époque (1870-1912). (3a ed.). Belém: Paka-Tatu.

SOUZA, R. F. (1998a). Espaço de educação e da civilização: origem dos grupos escolares no Brasil. In: SOUZA, R. F., VALDEMARIN, V. T., \& ALMEIDA, J. S. (Orgs.). O legado educacional do século XIX. Araraquara: UNESP.

SOUZA, R. F. (1998b). Templos de civilização: a implantação da escola primária graduada no Estado de São Paulo (1890-1910). São Paulo: UNESP. (Coleção Prismas).

THOMAZ NETO, M. O., \& BRAGA, O. F. (2002). O ensino de matemática na escola normal do Pará entre o final do século XIX e início do século XX. In: Anais do 2o Encontro de Pesquisa da UFPI. Teresina. Acessado em: http://leg.ufpi.br/subsiteFiles/ppged/arquivo s/files/eventos/evento2002/GT.13/GT13 12 2002.pdf.

Veiga, C. G. (2007). História da educação. São Paulo: Ática. (Ática Universidade).

Veríssimo, J. (1906). A educação nacional. (2a ed.). Rio de Janeiro: F. Alves.

VERÍSSIMO, J. (1891). A instrução pública no estado do Pará em 1890. Belém: Tipografia de Tavares Cardoso. VIDAL, D. G., \& FARIA FILHO, L. M. (2005). As lentes da história: estudos de história e historiografia da educação no Brasil. São Paulo: Autores Associados. (Memória da Educação). 